\title{
EUS-guided gastroenterostomy: Initial experience in a brazilian tertiary center
}

\author{
(D) Joel Fernandez de Oliveira ${ }^{1}$ \\ (D) Martin Andres Coronel Cordero ${ }^{1}$ \\ iD Gustavo Rosa de Almeida Lima1 \\ iD Gustavo Andrade de Paulo ${ }^{1}$ \\ iD Marcelo Simas de Lima' \\ (D) Bruno da Costa Martins ${ }^{1}$ \\ (iD) Ulysses Ribeiro $r r^{1}$ \\ (D) Fauze Maluf-Filho'
}

1. Instituto do Câncer do Estado de São Paulo (Icesp) da Faculdade de Medicina da Universidade de São Paulo (FMUSP), Serviço de Endoscopia Gastrointestinal, São Paulo, SP, Brasil.

http://dx.doi.org/10.1590/1806-9282.66.11.1521

\section{SUMMARY}

INTRODUCTION: EUS-guided gastroenterostomy (EUS-GE) is a novel procedure for palliation of malignant gastric outlet obstruction (GOO). Our aim was to evaluate the outcomes of this technique in our initial experience.

METHODS: Patients with GOO from our institute were included. Technical success was defined as the successful creation of a gastroenterostomy. Clinical success was defined as the ability to tolerate a soft diet after the procedure. We assessed adverse events and diet tolerance 1 month after the procedure.

RESULTS: Three patients were included. Technical and clinical success was achieved in all cases. There were no adverse events and good diet tolerance was observed 1 month after the procedure in the included patients.

CONCLUSION: EUS-GE is a promising treatment for patients with GOO.

KEYWORDS: Endosonography/methods. Gastric Outlet Obstruction. Gastroenterostomy/methods. Ultrasonography, Interventional/ methods.

\section{INTRODUCTION}

Gastric outlet obstruction (GOO) is a clinical condition characterized by nausea, vomiting, postprandial fullness, and abdominal pain as a consequence of mechanical obstruction of the gastrointestinal tract. This is more evident as a potential complication of pancreatic or distal gastric malignancy and can be present in up to $15 \%$ to $20 \%$ of patients with pancreatic adenocarcinoma ${ }^{\mathbf{1 , 2}}$.

Endoscopic ultrasound-guided gastrojejunostomy or gastroenterostomy (EUS-GE) has recently emerged as a procedure to treat patients with gastric outlet obstruction as an alternative to surgery or to standard endoscopic enteral stent placement ${ }^{3}$. This procedure is made by inserting a lumen-apposing metal stent (LAMS), from the gastric lumen to the small bowel distal to the obstruction, under endoscopic ultrasound (EUS) guidance.

In 2002, Fritscher-Ravens et al. ${ }^{4}$ first introduced the concept of endoscopic gastroenterostomy. However, the technique was not adopted due to the complexity

DATE OF SUBMISSION: 20-May-2020

DATE OF ACCEPTANCE: 02-Jul-2020

CORRESPONDING AUTHOR: Joel Fernandez de Oliveira

Av. Dr. Arnaldo, 251, Cerqueira César, São Paulo, SP, Brasil - 01246-000

Tel: +55 11 3893-2000

E-mail: jfoliveira1@gmail.com 
of the procedure. After the development of LAMS, Binmoeller and Shah ${ }^{5}$ introduced the EUS-GE for the first time using LAMS in an animal model in 2012, thus enabling the expansion of the technique.

Traditionally, surgical gastrojejunostomy has been the main treatment for benign and malignant GOO, despite the high complication rate of up to $40 \%{ }^{3,6}$. In addition, surgical treatment has some other limitations such as the prolonged recovery time that can delay the beginning of chemotherapy, gastroparesis, as well as the costs related to the procedure ${ }^{3}$.

In this study, we wanted to describe the results of our initial experience with EUS-guided gastroenterostomy.

\section{METHODS}

This study was approved by CONEP (Comissão Nacional de Ética em Pesquisa) on October $1^{\text {st }}, 2019$.

Patients $\geq 18$ years old, with a confirmed unresectable distal gastric, duodenal, or pancreaticobiliary malignancy, suffering from gastric outlet obstruction, with a gastric outlet obstruction score of $\leq 1$, and with a ECOG performance status $\leq 3$ were eligible for inclusion. They were included in the study after signing the informed consent. The exclusion criteria included coagulation disorders, life expectancy shorter than 1 month, linitis plastica, previous gastric surgery, and radiological signs of small bowel obstruction.

There are a few different techniques of EUS-GE ${ }^{7}$. We adopted the technique that employs a double-balloon catheter, described by Itoi et al. ${ }^{8}$.

Initially, a guidewire was passed through the proximal jejunum, leaving a overtube in the antrum or duodenal bulb. A balloon occlusion catheter (Tokyo Medical University type, Create Medic Co., Ltd., Yokohama, Japan) was passed through the guidewire to the proximal small intestine. This new catheter has six radiopaque beads at the distal end and two balloons, separated by $20 \mathrm{~cm}$, which when inflated fix a segment of the duodenum or jejunum. The segment of the small intestine between these two inflated balloons was then filled with contrast and methylene blue. Guided by EUS, a puncture of the distended small intestine between these two balloons was performed. The LAMS with an electrocautery-enhanced delivery system was directly implanted, creating the gastroenterostomy. The balloon catheter was then removed.

Patients were usually observed for 48 hours. Oral antibiotics (quinolone or a $3^{\text {rd }}$ generation cephalosporin) were administered for another 7 days after the procedure.
A liquid diet was started the next day and was advanced to a low residue (soft) diet for the next 1-2 days, as tolerated. Stents were left in place indefinitely.

Patients had a follow-up visit 1 month after the procedure.

Technical success was considered when the adequate introduction of the LAMS communicating the stomach and the jejunum was achieved.

The ingestion of a soft diet $48 \mathrm{~h}$ after the procedure was considered a clinical success.

Adverse events included gastrointestinal bleeding (melena or hematemesis requiring blood transfusion or any invasive intervention), abdominal sepsis (clinical signs of infection, and peritonitis with leucocytosis and/or elevated reactive-C-protein).

\section{RESULTS}

\section{Case 1}

An 80-year-old female patient, in follow-up by a palatal neoplasm, had complained for two months of postprandial fullness and nausea. She underwent a upper GI endoscopy that showed a stenosing lesion on the transition between the duodenal bulb and the second duodenal portion. Computed tomography was performed, which showed an infiltrative lesion in the pancreatic head, causing a duodenal obstruction. Discussed with a multidisciplinary team and defined by the EUS-FNB (fine needle biopsy) EUS-GE with $15 \mathrm{~mm}$ Hot-axios ${ }^{\mathrm{TM}}$, both with technical success and confirmation of pancreatic adenocarcinoma. At follow-up after 3 months, she had a good acceptance of the regular diet and no procedure-related adverse events.

FIGURE 1. A: EUS VIEW OF THE LAMS RELEASE. B: ENDOSCOPIC VIEW OF THE LAMS

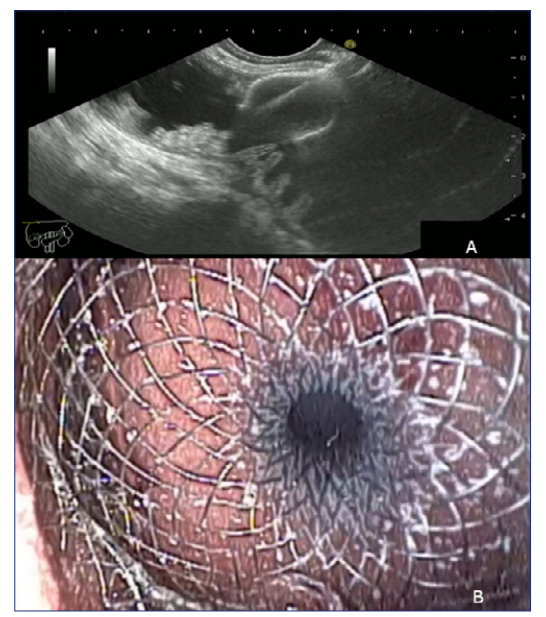




\section{Case 2}

A 75-year-old male patient, with locally advanced pancreatic neoplasia who had undergone endoscopic introduction of a biliary metal prosthesis, was admitted to the emergency room with abdominal pain, nausea, and vomiting. Endoscopy demonstrated gastric stasis and a stenotic lesion in the duodenum. He was then submitted to EUS-GE with $15 \mathrm{~mm}$ Hot-axios $^{\mathrm{TM}}$ with technical success. After 2 months, he reported good tolerance to a regular diet and no adverse events.

FIGURE 2. A: FLUOROSCOPY SHOWING GOOD PASSAGE OF CONTRAST FROM THE STOMACH TO THE JEJUNUM THROUGH THE LAMS. B: CT AFTER EUS-GE SHOWING THE LAMS

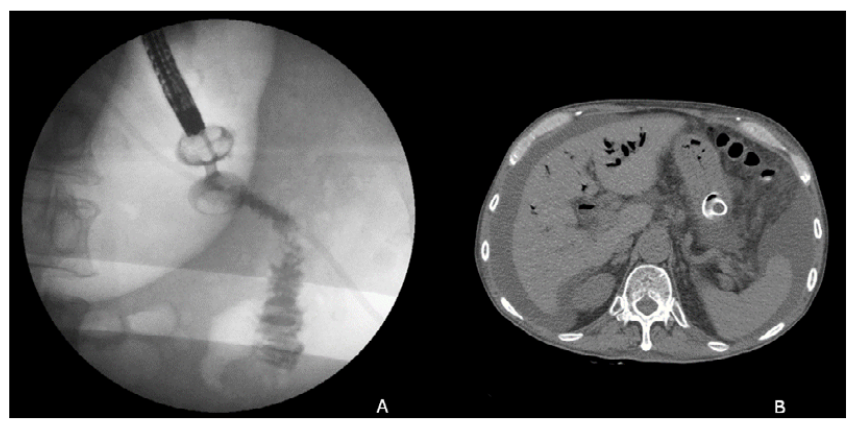

\section{Case 3}

A 72-year-old female patient followed up for metastatic pancreatic neoplasia who had previously undergone hepatic-jejunal anastomosis was admitted to the emergency room with GOO. Endoscopy revealed a stenotic lesion in the second duodenal portion. She was submitted to EUS-GE with $20 \mathrm{~mm}$ Hot-axios $^{\mathrm{TM}}$ with technical success. In the follow-up after 1 month, she presented good acceptance of a normal diet and no adverse events were observed.

FIGURE 3. A: INICIAL RELEASE OF LAMS. B: FINAL ASPECT OF EUS-GE

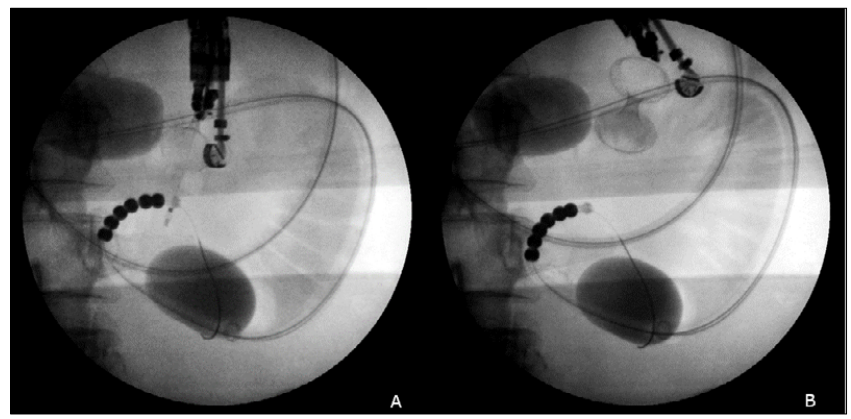

\section{DISCUSSION}

This is the first Brazilian series describing the initial results of EUS-guided gastroenteroanastomosis in patients with GOO. In our study, we achieved technical and clinical success in all three patients. All patients were discharged 48 hours after the procedure with good tolerance to a low residue diet and evolution to a regular diet. It is noteworthy that all the patients were admitted with clear symptoms of GOO. In addition, we did not observe any procedure-related adverse events.

It is important to note that in the first two cases, we used a $15 \mathrm{~mm}$ LAMS as the $20 \mathrm{~mm}$ was not yet available in Brasil. However, despite the good evolution of patients with a $15 \mathrm{~mm}$-diameter stent, we believe that a $20 \mathrm{~mm}$ LAMS might offer results more similar to a surgical gastroenterostomy.

Initial outcomes of EUS-GE have been promising, regardless of technique, and for a variety of different indications. In two recent systematic reviews and meta-analysis, one with 5 studies including 199 patients (21\% due to benign causes) and the second one with twelve studies including 285 patients, the reported technical success was $92 \%$ and clinical success, $90 \%$. Adverse events occurred in 5 to $12 \%$, and the re-intervention rate was $11 \%{ }^{9,10}$.

In a study by Ge et al. ${ }^{11}$ with 100 patients comparing EUS-GE and enteral stent placement in the palliation of malignant GOO, EUS-GE has a higher rate of initial clinical success (95.8\% vs. $76.3 \%)$ and a lower rate of stent failure requiring repeat intervention (32.0\% vs. 8.3\%). The enteral stent group trended towards increased adverse events (40.2\% vs. $20.8 \%$, p $=0.098$ ). The mean length of hospital stay was similar between the groups ${ }^{11}$. Another study by Chen et al. ${ }^{12}$ demonstrated a significantly lower risk of recurrence and reintervention in the EUS-GE group compared to the enteral stenting group (4.3\% vs $28.6 \%$ ).

In 2017, an international study compared EUS-GE versus laparoscopic gastrojejunostomy (Lap-GJ) ${ }^{13}$. The authors found a similar efficacy between the groups, although the EUS-GE group contained more complex patients. EUS-GE was cost-saving compared with Lap-GJ and caused less adverse events (12\% vs $41 \%)^{13}$.

Another possibility of using EUS-GE is in the treatment of afferent loop syndrome. This consists of the obstruction of the afferent loop, with fluid pressure building up in the loop and causing discomfort and nausea. The incidence of this complication after pancreaticoduodenectomy may be as high as $13 \%{ }^{14}$. A multicenter international experience on 18 patients 
showed that EUS treatment seems to be safe and effective.An indirect comparison with enteroscopy-assisted luminal stenting suggested that EUS treatment is associated with a reduced need for re-intervention ${ }^{15}$.

Despite the encouraging results, some requirements must be met before considering EUS-GE. A target area of the duodenal or jejunal lumen must be located by EUS near $(<2 \mathrm{~cm})$ the gastric wall due to the risk of incomplete apposition of the lumens by the LAMS. Another important point is to exclude the possibility of malignant invasion of the stomach wall because of the risk of bleeding and incomplete apposition of the stent. Severe obstruction of the outlet resulting in the inability to advance a guidewire to the jejunum may render the procedure unfeasible. Ascites can also make the procedure difficult. Finally, care must be taken to ensure that there is no luminal obstruction downstream and distal to the puncture site of the jejunum, especially in cases of peritoneal carcinomatosis or extensive lymphadenopathy ${ }^{16,17}$.

\section{CONCLUSION}

EUS-GE is a novel option for patients with GOO and our limited experience has demonstrated its feasibility and high clinical success. The results of retrospective studies suggest that EUS-GE may provide a more durable solution than enteral stenting and a less expensive solution than Lap-GJ with a shorter recovery time. Randomized controlled trials are warranted to support those views. In addition, EUS-GE is a technically challenging procedure that should only be carried out in centers with experience in therapeutic EUS.

\section{Author's Contribution}

All authors contributed equally to the concept of the paper, and the draft was prepared by Joel Fernandez de Oliveira and the final review was completed by Fauze Maluf Filho.

\section{RESUMO}

INTRODUÇão: A gastroenterostomia ecoguiada é um novo procedimento para paliação da obstrução maligna gastroduodenal. Nosso objetivo foi avaliar os resultados dessa técnica em nossa experiência inicial.

MÉTODOS: Foram incluídos pacientes com obstrução maligna gastroduodenal de nossa instituição. O sucesso técnico foi definido como a realização adequada de uma gastroenterostomia. O sucesso clínico foi definido como boa aceitação de dieta pastosa durante a internação. Os eventos adversos e a aceitação alimentar foram avaliados um mês após o procedimento.

RESULTADOS: Três pacientes foram incluídos. Os sucessos técnico e clínico foram alcançados em todos os casos. Não houve eventos adversos e a aceitação alimentar permaneceu adequada um mês após o procedimento nos pacientes incluídos.

CONCLUSÃO: O EUS-GE é um tratamento promissor para pacientes com obstrução maligna gastroduodenal.

PALAVRAS-CHAVE: Endossonografia/métodos. Obstrução da saída gástrica. Gastroenterostomia/métodos. Ultrassonografia de intervenção/ métodos.

\section{REFERENCES}

1. Tendler DA. Malignant gastric outlet obstruction: bridging another divide. Am J Gastroenterol. 2002;97(1):4-6.

2. van Heek NT, van Geenen RC, Busch OR, Gouma DJ. Palliative treatment in "peri"-pancreatic carcinoma: stenting or surgical therapy? Acta Gastroentero Belg. 2002;65(3):171-5.

3. Itoi $\mathrm{T}$, Baron $\mathrm{TH}$, Khashab MA, Tsuchiya $\mathrm{T}$, Irani $\mathrm{S}$, Dhir $\mathrm{V}$, et al. Technical review of endoscopic ultrasonography-guided gastroenterostomy in 2017. Dig Endosc. 2017;29(4):495-502.

4. Fritscher-Ravens A, Mosse CA, Mills TN, Mukherjee D, Park PO, Swain P. A through-the-scope device for suturing and tissue approximation under EUS control. Gastrointest Endosc. 2002;56(5):737-42.

5. Binmoeller KF, Shah JN. Endoscopic ultrasound-guided gastroenterostomy using novel tools designed for transluminal therapy: a porcine study. Endoscopy. 2012;44(5):499-503.

6. Khashab M, Alawad AS, Shin E), Kim K, Bourdel N, Singh VK, et al. Enteral stenting versus gastrojejunostomy for palliation of malignant gastric outlet obstruction. Surg Endosc. 2013;27(6):2068-75.
7. Irani S, Itoi T, Baron TH, Khashab M. EUS-guided gastroenterostomy: techniques from east to west. VideoGIE. 2020;5(2):48-50.

8. Itoi T, Itokawa F, Uraoka T, Gotoda T, Horii I, Goto O, et al. Novel EUSguided gastrojejunostomy technique using a new double-balloon enteric tube and lumen-apposing metal stent (with videos). Gastrointest Endosc. 2013;78(6):934-9.

9. McCarty TR, Garg R, Thompson CC, Rustagi T. Efficacy and safety of EUS-guided gastroenterostomy for benign and malignant gastric outlet obstruction: a systematic review and meta-analysis. Endosc Int Open. 2019;7(11):E1474-82.

10. Iqbal U, Khara HS, Hu Y, Kumar V, Tufail K, Confer B, et al. EUS-guided gastroenterostomy for the management of gastric outlet obstruction: a systematic review and meta-analysis. Endosc Ultrasound. 2020;9(1):16-23.

11. Ge PS, Young JY, Dong W, Thompson CC. EUS-guided gastroenterostomy versus enteral stent placement for palliation of malignant gastric outlet obstruction. Surg Endosc. 2019;33(10):3404-11. 
12. Chen YI, Itoi T, Baron TH, Nieto J, Haito-Chavez Y, Grimm IS, et al. EUSguided gastroenterostomy is comparable to enteral stenting with fewer re-interventions in malignant gastric outlet obstruction. Surg Endosc. 2017;31(7):2946-52.

13. Perez-Miranda M, Tyberg A, Poletto D, Toscano E, Gaidhane M, Desai AP, et al. EUS-guided gastrojejunostomy versus laparoscopic gastrojejunostomy: an international collaborative study. | Clin Gastroenterol. 2017;51(10):896-9.

14. Benallal DC, Hoibian S, Caillol F, Bories E, Presenti C, Ratone JP, et al. EUSguided gastroenterostomy for afferent loop syndrome treatment stent. Endosc Ultrasound. 2018;7(6):418-9.
15. Brewer Gutierrez OI, Irani SS, Ngamruengphong S, Aridi HD, Kunda R, Siddiqui A, et al. Endoscopic ultrasound-guided entero-enterostomy for the treatment of afferent loop syndrome: a multicenter experience. Endoscopy. 2018;50(9):891-5

16. Amin S, Sethi A. Endoscopic ultrasound-guided gastrojejunostomy. Gastrointest Endosc Clin N Am. 2017;27(4):707-13.

17. Dawod E, Nieto JM. Endoscopic ultrasound guided gastrojejunostomy. Transl Gastroenterol Hepatol. 2018;3:93. 